\title{
Referees for 2015
}

(C) Springer Science+Business Media Dordrecht 2015

The Journal of Ethics thanks both the members of its distinguished editorial board and the following philosophers for their excellent assistance to the journal by way of their service as referees:

David Adams

Scott Anderson

Sharon Bishop

Vanessa Carbonell

Michael Cholbi

John Christman

Randolph Clarke

R. A. Duff

David Enoch

Jody L. Graham

Jeffery Helmreich

Bruce Huebner

Nancy S. Jecker

Stephen Kershnar

Christopher Kulp

Jonathan Pugh

Linda Radzik

Tara Smith

Bonnie Steinbock

Cynthia Stark

James Stacey Taylor 